
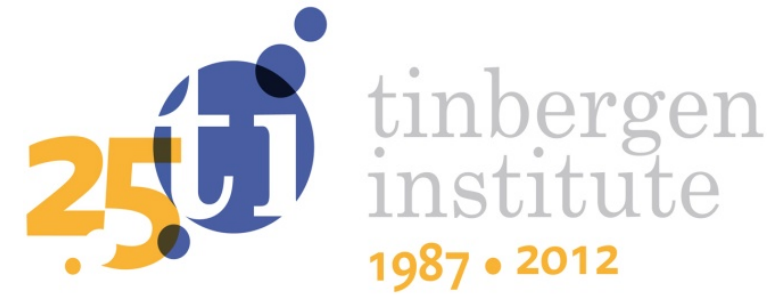

\title{
Capacity Choice under Uncertainty with Product Differentiation
}

Christiaan Behrens*

\author{
Mark Lijesen
}

Faculty of Economics and Business Aministration, VU University Amsterdam.

* Tinbergen Institute 
Tinbergen Institute is the graduate school and research institute in economics of Erasmus University Rotterdam, the University of Amsterdam and VU University Amsterdam.

More TI discussion papers can be downloaded at http://www.tinbergen.nl

Tinbergen Institute has two locations:

Tinbergen Institute Amsterdam

Gustav Mahlerplein 117

1082 MS Amsterdam

The Netherlands

Tel.: +31(0)205251600

Tinbergen Institute Rotterdam

Burg. Oudlaan 50

3062 PA Rotterdam

The Netherlands

Tel.: +31(0)10 4088900

Fax: $+31(0) 104089031$

Duisenberg school of finance is a collaboration of the Dutch financial sector and universities, with the ambition to support innovative research and offer top quality academic education in core areas of finance.

DSF research papers can be downloaded at: http://www.dsf.nl/

Duisenberg school of finance

Gustav Mahlerplein 117

1082 MS Amsterdam

The Netherlands

Tel.: +31(0)20 5258579 


\title{
The impact of product differentiation and uncertainty on capacity-then-price competition ${ }^{\text {索 }}$
}

\author{
Christiaan Behrens ${ }^{\mathrm{a}, \mathrm{b}, *}$, Mark Lijesen ${ }^{\mathrm{b}}$ \\ ${ }^{a}$ Tinbergen Institute, Gustav Mahlerplein 117, 1082 MS Amsterdam, The Netherlands \\ ${ }^{b}$ Department of Spatial Economics, VU University Amsterdam, De Boelelaan 1105, \\ $1081 \mathrm{HV}$ Amsterdam, The Netherlands
}

\begin{abstract}
We explore the characteristics of a capacity-then-price game for a duopoly market with product differentiation and stochastic demand. The analysis shows that a minimum threshold value for the level of vertical product differentiation exists, relative to horizontal product differentiation, for which existence of a Nash equilibrium in pure strategies is guaranteed. We find that when the quality and cost differences between the firms exactly offset each other, demand uncertainty causes equilibrium outcomes in capacities to become asymmetric. Without demand uncertainty, only a symmetric equilibrium can be established. This difference between stochastic and deterministic demand is the main driver behind our finding that if the regulator ignores the stochastic nature of demand, regulation lowers welfare for a large range of parameters, that is for approximately 10 per cent of the plausible parameter space.
\end{abstract}

Keywords: price competition, demand uncertainty, product differentiation, efficiency

JEL codes: D43, L11, L13

\footnotetext{
"This research is supported by Advanced ERC Grant OPTION \# 246969 and NWO grant 400-08-102.

${ }^{*}$ Corresponding author. Fax +3120 5986004, phone +31205984847.

Email addresses: c.l.behrens@vu.nl (Christiaan Behrens), m.g.lijesen@vu.nl (Mark Lijesen)
} 


\section{Introduction}

We analyse a two-stage duopoly game, where firms set capacities in the first stage and prices in the second. Demand is stochastic and becomes known only after the capacity stage, but before the pricing stage. Capacitythen-price games with demand uncertainty are relevant for a great number of industries where capacity is costly and outputs cannot be stored, such as scheduled transport and telecommunication services, electricity generation, hotels and so on. For example, Acemoglu et al. (2009) use the Internet, where service providers invest in capacities and then compete in prices, as their motivating example.

In their seminal article, Kreps and Scheinkman (1983) establish that capacity-then-price games yield profit maximising capacities equal to profit maximising quantities in a one-stage Cournot game. Their contribution has spurred a wave of research into capacity-then-price games focussing on the role of demand uncertainty and product differentiation. ${ }^{1}$ In our analysis, we take both demand uncertainty and product differentiation into account. Although prior literature includes various studies addressing product differentiation and demand uncertainty in capacity-then-price games separately, the combination of these two has not been studied before. Besides mere academic interests in these two extensions, both are realistic features of the above mentioned markets.

Several authors study demand uncertainty in the Kreps and Scheinkman framework. Gal-Or (1984) and De Frutos and Fabra (2011) allow for demand uncertainty with price-inelastic demand. In contrast, Hviid (1991), Gabszewicz and Poddar (1997), Reynolds and Wilson (2000) and Lepore (2012) allow for demand uncertainty with downward sloping demand. In short, these studies show that equilibria in pure strategies either fail to exist or only exist for specific configurations of the demand functions. ${ }^{2}$ However, the main insight by Kreps and Scheinkman, i.e. the equivalence between Bertrand and Cournot outcomes, has not been rejected.

Product differentiation is the other major extension of the Kreps and

\footnotetext{
${ }^{1}$ The particular focus on demand uncertainty might be fully attributed to Kreps and Scheinkman, because they conjecture that noise in the demand function will change their main findings dramatically.

${ }^{2}$ De Frutos and Fabra (2011) prove existence of the equilibrium by defining the capacity choice game submodular.
} 
Scheinkman framework drawing attention amongst scholars. Benassy (1989) identifies the impact of substitutability in Betrand-Edgeworth-Chamberlin models for given capacities. Yin and Ng (1997), Martin (1999) and Schulz (1999) include exogenous product differentiation into the Kreps and Scheinkman framework. An attractive consequence of including product differentiation is that the main result of Kreps and Scheinkman is then shown to hold without relying on an arbitrary rationing rule (Yin and $\mathrm{Ng}, 1997$ ).

We add to the literature by combining both extensions into one comprehensive model. Our model accounts for demand uncertainty before the capacity stage with a downward sloping demand function, like Reynolds and Wilson (2000) and Lepore (2012), and allows for substitutability between products of both firms, as suggested by Yin and $\mathrm{Ng}$ (1997). The firms in our duopoly might differ in (perceived) quality of their product and capacity costs. We find a unique equilibrium in pure strategies in both the pricing and capacity stage, provided the level of vertical product differentiation is sufficiently high.

A key finding is that under demand uncertainty equilibrium outcomes in capacities are asymmetric for quality and capacity costs differences that would yield symmetric outcomes in a setting without demand uncertainty. In particular, the capacity costs prevent the high-quality firm from serving occasional high levels of demand, leaving more room for the low-quality firm to serve the market than it would have without demand uncertainty. We further show that if a welfare maximising regulator ignores the stochastic nature of demand, regulation yields lower welfare than the unregulated market outcome for a large range of feasible parameter values. Only in approximately 10 per cent of all possible scenarios of quality and cost differences, this so-called naive regulation would outperform the unregulated market. This clearly highlights the importance of taking into account the stochastic nature of demand.

The remainder of this article is organised as follows. Section 2 outlines the model, followed by a discussion of the existence of equilibria in pure strategies in Section 3. We describe the pricing stage in Section 4 and the capacity stage in Section 5. In Section 6, we provide a numerical analysis to address the impact of demand uncertainty and product differentiation on market and regulatory performance. The final section, Section 7, concludes. 


\section{Basic model}

\subsection{Model set-up}

Our model follows the framework used in Kreps and Scheinkman (1983), but adds demand uncertainty and exogenous product differentiation. Two firms play a capacity-then-price game. Firms set capacities in the first stage and prices in the second stage. In both stages the firms act simultaneously. A quadratic utility function of the representative consumer implies the following: ${ }^{3}$

$$
\begin{aligned}
& p_{1}\left(z_{1}, z_{2}, b, \varphi, \alpha\right)=\alpha-\left(z_{1}+\varphi z_{2}\right) / b, \\
& p_{2}\left(z_{1}, z_{2}, b, \varphi, \theta, \alpha\right)=\theta \alpha-\left(\varphi z_{1}+z_{2}\right) / b,
\end{aligned}
$$

where $z_{i}$ represents the firm specific output, $\alpha$ the reservation price, and $b$ is the direct demand sensitivity. We assume this demand sensitivity to be equal for both goods. The degree of horizontal product differentiation is captured by $\varphi$, which ranges from 0 for independent goods to 1 for perfect substitutes. ${ }^{4}$ Vertical product differentiation is represented by $\theta$ where a unit value indicates that the goods are not differentiated. Without loss of generality, we appoint firm 1 as the high-quality firm by assuming $\theta<1$. $^{5}$ Additionally, we assume that $\theta / \varphi$ is sufficiently large to ensure that firm 2 will install a positive capacity. For ease of exposition and interpretation, the parameters $\alpha$ and $b$ are scaled in such a way that utility is measured in monetary terms. Both determine the level of demand. Throughout this analysis, we focus on demand uncertainty in the level of demand through stochasticity in $b$, assuming that the reservation price is constant for different realised levels of demand.

Firm profits are equal to revenue, $p_{i} z_{i}$, minus costs. Firms maximise their profits by setting capacities, $x_{i}$, in the first stage and prices, $p_{i}$, in the second stage of the model. Output is constrained such that $z_{i} \leq x_{i}$. Firms face a cost of $c_{i}$ per unit of capacity and are assumed to have no other costs. So, $C_{i}\left(c_{i}, x_{i}\right)=c_{i} x_{i}$. We allow these costs to differ between firms. The only formal restriction on the cost parameter is that capacity

\footnotetext{
${ }^{3}$ See, for example, Vives (1999).

${ }^{4}$ Formally, $0 \leq \varphi \leq 1$ ensures that the two goods are substitutes and that the quadratic utility function is strictly concave.

${ }^{5}$ Quality may also refer to perceived quality or desirability. we relate vertical product differentiation to the reservation price for easy comparison of high cost, high-quality firms with low cost,low-quality firms.
} 
costs are strictly positive for both firms. Additionally, one may argue that in practice the higher quality firm is likely to have higher costs per unit of capacity. Examples of firms with higher (perceived) quality in combination with higher capital costs include legacy versus low-cost airlines, low- versus high end hotels, and - if consumers mind environmental aspects - renewable versus traditional electricity generation.

Kreps and Scheinkman (1983) establish that capacity-then-price games lead to Cournot outcomes, motivating the use of the single stage Cournot outcome of our model as a benchmark for further analysis. If demand is deterministic, the Cournot outcome becomes:

$$
\begin{aligned}
& x_{1, C}^{*}\left(\bar{b}, c_{1}, c_{2}, \cdot\right)=\bar{b} \frac{2\left(\alpha-c_{1}\right)-\varphi\left(\theta \alpha-c_{2}\right)}{4-\varphi^{2}}, \\
& x_{2, C}^{*}\left(\bar{b}, c_{1}, c_{2}, \cdot\right)=\bar{b} \frac{2\left(\theta \alpha-c_{2}\right)-\varphi\left(\alpha-c_{1}\right)}{4-\varphi^{2}},
\end{aligned}
$$

where $\bar{b}$ is a positive parameter equal to the mean of the probability function of $b$ if demand uncertainty is included in the model as we will discus below. Without demand uncertainty, the capacities are equal to the outputs for both firms in the equilibrium: $z_{i}=x_{i}$. The model is asymmetric for $\theta<1$, unless the cost difference per unit of capacity equals the relative difference in reservation prices, $c_{1}-c_{2}=(1-\theta) \alpha$. The level of demand and degree of horizontal product differentiation do not alter this condition.

\subsection{Demand uncertainty}

We now introduce demand uncertainty into the model. When setting capacities, firms know that different demand states will occur after capacities are chosen. Firms thus base their capacity decisions on a probability function of $b$, with support $\left(0, \alpha^{-1}\right]$ and mean $\bar{b} .{ }^{6}$ The expected profit for firm $i$ equals:

$$
\pi_{i}\left(x_{1}, x_{2}, \cdot\right)=\int_{0}^{\alpha^{-1}} p_{i}\left(x_{1}, x_{2}, b, \cdot\right) z_{i}\left(x_{1}, x_{2}, b, \cdot\right) f(b) d b-c_{i} x_{i}
$$

Firms maximise expected profits by setting capacities in the first stage and prices in the second, with outputs following from capacities, prices and

\footnotetext{
${ }^{6}$ The upper bound $\alpha^{-1}$, only scales the model in the output dimension and ensures that demand cannot exceed 1 for any given positive price.
} 
states of the world. The next section discusses how the states of the world, the level of demand and capacities are interrelated. The model is solved by backward induction.

Apart from the profits of each firm, we look at the efficiency of the resulting equilibria over the different degrees of product differentiation, costs, and demand uncertainty. For the latter, we compare the efficiency of the standard Cournot outcome as shown in (2) and the results based on optimisation of (3). In line with earlier work, see e.g., Acemoglu et al. (2009), efficiency is defined as the ratio of social surplus in equilibrium relative to the first-best outcome, with social surplus (as measure of welfare) defined as:

$W\left(x_{1}, x_{2}, \cdot\right)=\int_{0}^{\alpha^{-1}}\left(\int_{0}^{z_{1}^{*}(b, \cdot)} p_{1}(\zeta, \cdot) d \zeta+\int_{0}^{z_{2}^{*}\left(x_{1}, b, \cdot\right)} p_{2}(\zeta, \cdot) d \zeta\right) f(b) d b-c_{1} x_{1}-c_{2} x_{2}$,

where $z_{1}^{*}$ and $z_{2}^{*}$ are (social) optimal values of output determined in the pricing stage subject to the capacity restrictions $z_{i} \leq x_{i}$. The term in between brackets denotes the consumer benefit for output 1 and 2 respectively, with inverse demand $p_{i}(\cdot)$ defined as in (1). We discuss the first-best outcome at length in Section 5.2.

\section{Existence of pure strategy equilibria}

The existence of equilibria in pure strategies is not generally guaranteed in capacity-then-price games with uncertain demand. At the core of the problem lies the incentive in Bertrand-Edgeworth models for one firm, to increase its price if the other firm's output is near capacity. As a result, the competitor's capacity constraint becomes binding, and the firm earns residual monopoly profits instead of Bertrand duopoly profits. Benassy (1989, p. 227) establishes that for an equilibrium to exist, it should be impossible or irrational for any firm to saturate the capacity of its competitor(s) by raising its own price. In the case of deterministic demand, firms produce at full capacity by construction, so the problem does not arise, and hence existence of a pure strategy equilibrium is guaranteed.

If demand is uncertain and capacity is costly, firms do not produce at 
full capacity for all levels of demand. ${ }^{7}$ Three situations in the price-stage may apply, and hence three parameter regions can be distinguished. The boundaries for each region depend on the level of demand $b$, relative to the endogenous capacities $x_{1}$ and $x_{2}$. In the first region, demand is too low for any firm to produce at full capacity, and firms play unrestricted Bertrand in the price stage of the game. In the third region, demand is sufficiently high to have both firms produce at full capacity and charge clearing prices corresponding to their capacities, which boils down to the results reported by Kreps and Scheinkman (1983). ${ }^{8}$ The problem lies however in the region between high and low demand, where at least one of the firms has an incentive to saturate the other's capacity.

The following example illustrates this point. Consider a Bertrand duopoly without product differentiation, and both firms producing near capacity. Since neither firm is capacity restricted, both firms make zero profit in the Bertrand-Nash equilibrium. Either firm can, however, obtain a positive profit by setting a price above marginal costs, as this will saturate the other firm's capacity, implying that some consumers cannot switch to the other firm. For example, suppose firm 1 raises its price to saturate firm 2. This provides an incentive for firm 2, who is now capacity restricted, to raise its price as well. Actually, firm 2 may raise its price to just undercut firm 1's price without losing consumers, because the products are pure substitutes. In turn, this provides an incentive for firm 1 to undercut firm 2's price. We then have the non-existence result as established by Benassy (1989), which may also hold for imperfect substitutes (Benassy, 1989, theorem 3).

Proposition 3.1. A Nash equilibrium in pure strategies in the pricing stage exists if and only if $\theta \leq \varphi /\left(2-\varphi^{2}\right)$.

Proof. We start by showing that the equilibrium in pure strategies does not exist if $\theta>\varphi /\left(2-\varphi^{2}\right)$. Following Benassy (1989), it is sufficient to prove that both firms produce positive outputs if neither firm is capacity restricted. Rewriting (1) yields the firm specific demand functions without capacity restrictions:

\footnotetext{
${ }^{7}$ For low levels of demand, capacity utilization will be under-utilized, whereas for high levels of demand it may be fully utilized.

${ }^{8}$ Based on the first and third region only, Young (2010) claims to have found an equilibrium in pure strategies. However, this finding is based on ignoring the intermediate region in which pure strategy equilibria in prices fail to exist.
} 


$$
\begin{aligned}
& D_{1}\left(p_{1}, p_{2}, b, \cdot\right)=\frac{b\left(\alpha(1-\theta \varphi)-p_{1}+\varphi p_{2}\right.}{1-\varphi^{2}}, \\
& D_{2}\left(p_{1}, p_{2}, b, \cdot\right)=\frac{b\left(\alpha(\theta-\varphi)-p_{2}+\varphi p_{1}\right.}{1-\varphi^{2}},
\end{aligned}
$$

The profit function equals the demand as defined in (5) multiplied by the corresponding price. Taking the first order conditions of these with respect to prices, solving for prices and substituting these prices in (5), yields the equilibrium prices and outputs for each firm:

$$
\begin{gathered}
p_{1}^{*}(\cdot)=\frac{\alpha\left(2-\varphi^{2}-\varphi \theta\right)}{4-\varphi^{2}}, \quad p_{2}^{*}(\cdot)=\frac{\alpha\left(2 \theta-\varphi^{2} \theta-\varphi\right)}{4-\varphi^{2}}, \\
z_{1}^{*}(b, \cdot)=\frac{\alpha b\left(2-\varphi^{2}-\varphi \theta\right)}{\left(4-\varphi^{2}\right)\left(1-\varphi^{2}\right)}, \quad z_{2}^{*}(b, \cdot)=\frac{\alpha b\left(2 \theta-\varphi^{2} \theta-\varphi\right)}{\left(4-\varphi^{2}\right)\left(1-\varphi^{2}\right)},
\end{gathered}
$$

It follows directly that $\theta>\varphi /\left(2-\varphi^{2}\right)$ guarantees positive outputs for both firms. This gives rise to the non-existence problem as identified by Benassy (1989), because both firms have an incentive to just undercut the competitor's price.

For the equilibrium in pure strategies to exist, we need to establish that the high-quality firm does not have the incentive to saturate the capacity of the low-quality firm. If the high-quality firm chooses not to saturate the competitor's capacity, it will act like a contested monopoly, and set a limit price. The profits are defined by multiplying the equilibrium price in (6) and output in (7) of the high-quality firm:

$$
\pi_{1, C M}^{*}(b, \cdot)=\alpha^{2} b \theta(\varphi-\theta) / \varphi^{2}-c_{1} x_{1},
$$

where subscript $C M$ refers to the contested monopoly strategy. ${ }^{9}$

\footnotetext{
${ }^{9} \mathrm{~A}$ special case arises if $\theta \leq \varphi / 2$. In this case, the low-quality firm cannot produce profitably whilst setting a positive price for its output. As a result, the contested monopoly becomes a pure monopoly if both firms are not capacity restricted. By comparing pure monopoly profits $\pi_{1, M}^{*}(b, \cdot)=(1 / 4) \alpha^{2} b$ with the contested monopoly profits as defined in (8), we can show that for $\pi_{1, C M}^{*}>\pi_{1, M}^{*}$ to hold, it is required that $\theta>(1 / 2) \varphi$. It is only profitable for firm 1 to act as a monopolist if firm 2 cannot produce profitably at the
} 
If firm 1 does saturate firm 2's capacity, it acts as a residual monopolist. Firm 2's best response function in prices in that case equals:

$$
p_{2, R M_{1}}(\cdot)=\left(\alpha(\theta-\varphi)+\varphi p_{1, R M_{1}}\right) / 2,
$$

where subscript $R M_{1}$ refers to the residual monopoly strategy of firm 1 . Rewriting this function for $p_{1, R M_{1}}$ and substituting the clearing price $p_{2, R M_{1}}^{*}$ for which $D_{2}\left(p_{2, R M_{1}}^{*}\right)=x_{2}$, yields the equilibrium price for firm 1:

$$
p_{1, R M_{1}}^{*}\left(x_{2}, b, \cdot\right)=\frac{\alpha(\varphi-\theta)+2 p_{2, R M_{1}}^{*}}{\varphi}=\frac{\alpha b(\varphi-\theta)+2 x_{2}\left(1-\varphi^{2}\right)}{b \varphi} .
$$

Substituting this price into the demand function yields equilibrium output: $z_{1, R M_{1}}^{*}\left(x_{2}, b, \cdot\right)=\left(\alpha b \theta-x^{2}\left(2-\varphi^{2}\right)\right) / \varphi$. Therefore the profit for firm 1 acting as a residual monopolist equals:

$$
\pi_{1, R M_{1}}^{*}\left(x_{2}, b, \cdot\right)=\frac{\left(\alpha b \theta-x_{2}\left(2-\varphi^{2}\right)\right)\left(\alpha b(\varphi-\theta)+2 x_{2}\left(1-\varphi^{2}\right)\right)}{b \varphi^{2}} .
$$

It is only rational for firm 1 to saturate firm 2's capacity if $\pi_{1, C M}^{*}<\pi_{1, R M_{1}}^{*}$. This implies that for:

$$
\theta<\frac{\left(2-\varphi^{2}\right)\left(\alpha b \varphi+2 x_{2}\left(1-\varphi^{2}\right)\right)}{\alpha b\left(4-3 \varphi^{2}\right)}
$$

firm 1 does not have the incentive to saturate firm 2's capacity. It is easy to show that this condition is always satisfied for $\theta \leq \varphi /\left(2-\varphi^{2}\right)$ : substituting $\bar{\theta}=\varphi /\left(2-\varphi^{2}\right)$ as an upper bound of $\theta$ in (11) yields:

$$
\bar{\theta}-\frac{\left(2-\varphi^{2}\right)\left(\alpha b \varphi+2 x_{2}\left(1-\varphi^{2}\right)\right)}{\alpha b\left(4-3 \varphi^{2}\right)}=\frac{\left(1-\varphi^{2}\right)\left(\alpha b \varphi^{3}-2\left(2-\varphi^{2}\right)^{2}\right)}{\alpha b\left(2-\varphi^{2}\right)\left(4-3 \varphi^{2}\right)}<0,
$$

since $\alpha b \varphi^{3}<2\left(2-\varphi^{2}\right)^{2}$, expression (12) is negative for any level of demand $b$ and for $0 \leq \varphi \leq 1$.

monopoly price. Substituting this monopoly price $p_{1, M}^{*}(\cdot)=(1 / 2) \alpha$, into the best response function of firm 2 yields firm 2's equilibrium price: $p_{2, M}^{*}(\cdot)=\alpha(2 \theta-\varphi) / 4$. Obviously, $\theta \leq(1 / 2)$ yields a zero or negative equilibrium price for firm 2 . Whether the high-quality firm acts as a contested or pure monopoly does not alter the analysis of price competition where at least one firm is constrained in capacity. 
Proposition 3.1 sets the stage for the remainder of this article, focusing on what we will call the mainly vertical product differentiation case, for which the existence of a Nash equilibrium in pure strategies is guaranteed. Such a setting is relevant in real markets such as air transport (low-cost versus legacy carriers) and hotels (low-end versus high-end hotels). Throughout the subsequent analysis, the degree of vertical product differentiation is bounded by a lower bound $\underline{\theta}$ guaranteeing the capacity of the low-quality firm to be positive, and by an upper bound $\bar{\theta}$ guaranteeing the existence of a Nash equilibrium in pure strategies.

\section{Pricing stage}

After both firms installed their capacity and the actual level of demand $b$ has been revealed to both firms, we can distinguish between three levels of demand: low, medium, and high demand. We categorize these levels of demand by the nature of strategic interaction occurring in each region: contested monopoly, residual monopoly and Bertrand Edgeworth duopoly respectively. ${ }^{10}$ The boundaries for each demand region depend on the level of demand $b$ relative to installed capacities $x_{1}$ and $x_{2}$, which are to be taken as exogenous in the pricing stage.

\subsection{Contested monopoly}

Proposition 4.1. For demand levels defined by $b_{C M} \leq x_{1} \varphi / \alpha \theta$ the lowquality firm, firm 2, will not produce and the high-quality firm, firm 1, will set a limit price equal to $p_{1, C M}^{*}(\cdot)=\alpha(\varphi-\theta) / \varphi$, resulting in equilibrium output $z_{1, C M}^{*}(b, \cdot)=\alpha b \theta / \varphi$.

Proof. It follows directly from Proposition 3.1 that the firm 2 has zero output. However, firm 1 has to take into account potential production of firm 2 . Therefore, firm 1 offers output at the limit price at which firm 2 will just not produce. This limit price as mentioned in Proposition 4.1 can be found by setting firm 2's best response in prices equal to zero and solve for $p_{1, C M}^{*}(\cdot)$. Substituting $p_{1, C M}^{*}(\cdot)$ and $z_{2}=0$ into firm 1's demand function gives the

\footnotetext{
${ }^{10}$ Note that the only resemblance between our definition of three regions in the pricing stage and the definition as used in, for example, De Frutos and Fabra (2011) and Osborne and Pitchik (1986), is the fact that both sets of regions depend on demand and capacity characteristics.
} 
equilibrium output $z_{1, C M}^{*}(b, \cdot)$. The upper bound of the first region, as defined in Proposition 4.1 , can be found by equating $z_{1, C M}^{*}(b, \cdot)$ to firm 1's capacity and solve for $b$.

Both firm 1's equilibrium price and output are increasing in the degree of horizontal differentiation, implying that firm 1's profits are higher if the outputs are more horizontally differentiated. The price is positively related to the reservation price $\alpha$ and to the level of vertical product differentiation $\theta$. A smaller difference in the (perceived) quality between the two firms, indicated by a higher value of $\theta$, leaves less room for the high-quality firm to reap quality rents, which is what one would expect from a limit price. For $\theta>1 / 2$ the profit of firm 1 increases in the degree of vertical differentiation.

\subsection{Residual monopoly}

Proposition 4.2. For demand levels defined by $\frac{x_{1} \varphi}{\alpha \theta}<b_{R M} \leq \frac{\left(x_{1} \varphi+2 x_{2}\right)}{\alpha \theta}$ firm 1 will produce at full capacity with $p_{1, R M}^{*}\left(x_{1}, b, \cdot\right)=\frac{\alpha b(2-\theta \varphi)-x_{1}\left(2-\varphi^{2}\right)}{2 b}$ and firm 2 serves residual demand $z_{2, R M}^{*}\left(x_{1}, b, \cdot\right)=\frac{\alpha b \theta-x_{1} \varphi}{2}$ at $p_{2, R M}^{*}\left(x_{1}, b, \cdot\right)=\frac{\alpha b \theta-x_{1} \varphi}{2 b}$.

Proof. Following Proposition 3.1, it is rational for the high-quality firm, firm 1, to produce at full capacity if the level of demand exceeds the threshold level as defined in Proposition 4.1. This implies that the low-quality firm, firm 2, serves residual demand as a monopolist. Substituting $z_{1}^{*}=x_{1}$ into the inverse demand function and rewriting for $z_{2}$ yields the demand function for the output of firm 2: $D_{2, R M}\left(x_{1}, p_{2, R M}, b, \cdot\right)=\alpha b \theta-b p_{2, R M}-x_{1} \varphi$. The profit for firm 2 simply equals price times demand minus capacity costs. The profit maximising price as mentioned in Proposition 4.2 for firm 2 now follows directly from rewriting the first order condition. Substituting $p_{2, R M}^{*}\left(x_{1}, b, \cdot\right)$ into the demand function for firm 2 yields the accompanying equilibrium output. Since firm 1 is capacity restricted, its optimal price is the clearing price given firm 2's optimal behaviour. Substituting $z_{1}=x_{1}$ and $z_{2, R M}^{*}\left(x_{1}, b, \cdot\right)$ into the inverse demand function for output 1 as defined in (5) gives $p_{1, R M}^{*}\left(x_{1}, b, \cdot\right)$. The lower bound of this residual demand region follows directly from Proposition 4.1 , whereas the upper bound is determined by equating $z_{2, R M}^{*}\left(x_{1}, b, \cdot\right)$ to firm 2's capacity $x_{2}$ and solve for $b$.

Both the equilibrium price and output for firm 2 are increasing in the level of demand $b$, and decreasing in firm 1's capacity. Vertical product differentiation decreases firm 2's profits because it gives firm 1 more possibilities to exercise its contestable monopoly power in the first region. The equilibrium 
price of firm 1 is positively related to the level of vertical product differentiation (or the quality difference) and negatively to its own capacity, which is a common funding in capacity restricted price games.

\subsection{Bertrand Edgeworth duopoly region}

If demand exceeds the threshold level as given in Proposition 4.2, both firms are capacity restricted. Stated otherwise, the outputs associated to their optimal pricing exceed their installed capacities.

Proposition 4.3. For demand levels defined by $b_{B E}>\left(x_{1} \varphi+2 x_{2}\right) / \alpha \theta$, both firms will produce at full capacity $z_{i, B E}^{*}=x_{i}$, yielding equilibrium clearing prices: $p_{1, B E}^{*}\left(x_{1}, x_{2}, b, \cdot\right)=\alpha-\frac{x_{1}+x_{2} \varphi}{b}$ and $p_{2, B E}^{*}\left(x_{1}, x_{2}, b, \cdot\right)=\alpha \theta-\frac{x_{1} \varphi+x_{2}}{b}$.

Proof. The proof follows straightforwardly from the boundary for the level of demand mentioned in Proposition 4.2. For this and higher levels of $b$, the profit maximising output of both firms exceeds their capacities, implying that they will produce at full capacity. Given that both firms produce at full capacity, it is rational for them to set clearing prices to maximise profits. The equilibrium clearing prices can be found by substituting capacities for outputs in the inverse demand functions.

Both prices are negatively related to the firms' joint capacity (corrected for horizontal product differentiation), which is a common feature of Bertrand Edgeworth models.

\section{Capacity stage}

\subsection{Profit maximising capacities}

Having expressed all equilibrium prices and outputs in terms of capacity and the level of demand $b$ in Section 4, we can now solve the capacity stage. To solve for the capacity stage, we first substitute the established equilibrium prices and outputs for each demand region into the profit function for firm 1 
as defined in (3):

$$
\begin{aligned}
\pi_{1}\left(x_{1}, x_{2}, \cdot\right) & =\int_{0}^{b_{C M}\left(x_{1}, \cdot\right)} z_{1, C M}^{*}(b, \cdot) p_{1, C M}(\cdot)^{*} f(b) d b \\
& +\int_{b_{C M}\left(x_{1}, \cdot\right)}^{b_{R M}\left(x_{1}, x_{2}, \cdot\right)} x_{1} p_{1, R M}^{*}\left(x_{1}, b, \cdot\right) f(b) d b \\
& +\int_{b_{R M}\left(x_{1}, x_{2}, \cdot\right)}^{\alpha^{-1}} x_{1} p_{1, B E}^{*}\left(x_{1}, x_{2}, b, \cdot\right) f(b) d b-c_{1} x_{1},
\end{aligned}
$$

and for firm 2:

$$
\begin{aligned}
\pi_{2}\left(x_{1}, x_{2}, \cdot\right) & =\int_{b_{C M}\left(x_{1}, \cdot\right)}^{b_{R M}\left(x_{1}, x_{2}, \cdot\right)} z_{2, R M}^{*}\left(x_{1}, b, \cdot\right) p_{2, R M}^{*}\left(x_{1}, b, \cdot\right) f(b) d b \\
& +\int_{b_{R M}\left(x_{1}, x_{2}, \cdot\right)}^{\alpha^{-1}} x_{2} p_{2, B E}^{*}\left(x_{1}, x_{2}, b, \cdot\right) f(b) d b-c_{2} x_{2} .
\end{aligned}
$$

The three separate integrals in (13) reflect the relevant three regions contested monopoly, residual monopoly and Bertrand Edgeworth duopoly for firm 1, whereas the two integrals in (14) reflect the ones relevant for firm 2. Note that the domain of integration for each region depends on the installed capacities by each firm. Both firms maximise their expected profits by setting capacities simultaneously.

Proposition 5.1. There exists a unique profit maximising equilibrium in the capacity stage. In this equilibrium, both firms install that level of capacity for which the marginal revenue of capacity is equal to the marginal cost of capacity.

Proof. Applying Leibniz Integration Rule to (13) and (14) allows us to write 
the first order conditions for profit maximisation as follows:

$$
\begin{aligned}
\frac{\partial \pi_{1}\left(x_{1}, x_{2}, \cdot\right)}{\partial x_{1}} & =\int_{b_{C M}\left(x_{1}, \cdot\right)}^{b_{R M}\left(x_{1}, x_{2}, \cdot\right)} \frac{\partial}{\partial x_{1}} x_{1} p_{1, R M}^{*}\left(x_{1}, b, \cdot\right) f(b) d b \\
& +\int_{b_{R M}\left(x_{1}, x_{2}, \cdot\right)}^{\alpha^{-1}} \frac{\partial}{\partial x_{1}} x_{1} p_{1, b e}^{*}\left(x_{1}, x_{2}, b, \cdot\right) f(b) d b-c_{1}=0
\end{aligned}
$$

and for firm 2:

$$
\begin{aligned}
\frac{\partial \pi_{2}\left(x_{1}, x_{2}, \cdot\right)}{\partial x_{2}} & =\int_{b_{C M}\left(x_{1}, \cdot\right)}^{b_{R M}\left(x_{1}, x_{2}, \cdot\right)} \frac{\partial}{\partial x_{2}} z_{2, R M}^{*}\left(x_{1}, b, \cdot\right) p_{2, R M}^{*}\left(x_{1}, b, \cdot\right) f(b) d b \\
& +\int_{b_{R M}\left(x_{1}, x_{2}, \cdot\right)}^{\alpha^{-1}} \frac{\partial}{\partial x_{2}} x_{2} p_{2, b e}^{*}\left(x_{1}, x_{2}, b, \cdot\right) f(b) d b-c_{2}=0 .
\end{aligned}
$$

The first order conditions in (15) and (16) show that both firms set marginal revenues of capacity equal to marginal costs of capacity. By construction, capacity is never binding for firm 1 in the contested monopoly region, and hence marginal revenue of capacity equals zero in that demand region. ${ }^{11}$ It is straightforward to verify that each first order condition has a unique solution in capacity. For each marginal revenue term within a specific demand region, we know that it is decreasing in the relevant capacity over the whole domain of the integral. ${ }^{12}$ At the boundary value $b_{R M}$, the marginal revenue is equal for both regions of demand. Therefore, total marginal revenue is monotonically decreasing in capacity, whereas marginal costs of capacity are constant, implying a unique solution in capacity.

\subsection{Welfare maximizing capacities}

We now characterise the normative first-best solution of the above defined capacity-then-price game. This solution includes both optimal capacity and

\footnotetext{
${ }^{11}$ Firm 2 has no revenues in the contested monopoly region.

${ }^{12}$ For example, in the residual monopoly demand region firm 1 revenues equal: $x_{1}\left(\alpha b(2-\theta \varphi)-x_{1}\left(2-\varphi^{2}\right)\right) / 2 b$. Hence, the marginal revenue $\left(\alpha b(2-\theta \varphi)-2 x_{1}\left(2-\varphi^{2}\right)\right) / 2 b$ is decreasing in $x_{1}$.
} 
accompanying output levels. Looking only at cases where $\theta \leq \varphi /\left(2-\varphi^{2}\right)$, one needs to take into account whether the (perceived) qualitative superior output has strictly higher capacity costs or not.

Proposition 5.2. For $c_{1} \leq c_{2}$, a unique welfare maximizing equilibrium in the capacity stage exists. In this equilibrium, the high-quality firm should install that level of capacity for which the marginal benefit of capacity is equal to marginal cost of capacity, whereas the low-quality firm should not install any capacity.

Proof. Assuming that the two firms have the same production costs and only differ in (perceived) quality and capacity costs, it is straightforward that for $c_{1} \leq c_{2}$ only the (perceived) qualitative superior output should be produced to maximise welfare. ${ }^{13}$ If demand is low, the social optimal output follows from maximizing $\int_{0}^{z_{1}} p_{1}(\zeta, b, \cdot) d \zeta$ with respect to $z_{1}$. Using the fact that $z_{2}=0$, the optimal output yields: $z_{1}^{*}=\alpha b$. This implies that the capacity restriction is binding when demand is high, that is: $b>x_{1} \alpha^{-1}$. We refer to this boundary value as $b_{l}$. Hence, the applicable welfare function in the capacity stage is:

$$
W\left(x_{1}, \cdot\right)=\int_{0}^{b_{l}\left(x_{1}, \cdot\right)} \int_{0}^{z_{1}^{*}(b, \cdot)} p_{1}(\zeta, b, \cdot) d \zeta f(b) d b+\int_{b_{l}\left(x_{1}, \cdot\right)}^{\alpha^{-1}} \int_{0}^{x_{1}} p_{1}(\zeta, b, \cdot) d \zeta f(b) d b-c_{1} x_{1},
$$

where $p_{1}(\zeta, b, \cdot)$ follows directly from (1). Applying Leibniz Integration Rule yields the following first order condition for welfare maximisation:

$$
\frac{\partial W\left(x_{1}, \cdot\right)}{\partial x_{1}}=\int_{b_{l}\left(x_{1}, \cdot\right)}^{\alpha^{-1}}\left(\frac{\partial}{\partial x_{1}} \int_{0}^{x_{1}} p_{1}(\zeta, b, \cdot) d \zeta\right) f(b) d b-c_{1}=0 .
$$

In (18), the term within brackets is equal to the marginal consumers' benefit of capacity installed by the high-quality firm, which is equal to $\alpha-x_{1} / b$. Hence, (18) implies that the marginal benefit of capacity needs to be equal to the marginal cost of capacity. The marginal benefit of an extra unit of capacity is, just as the marginal revenue, equal to zero if the capacity constraint is not binding.

\footnotetext{
${ }^{13}$ The assumed symmetry in production costs does not alter our main result.
} 
Proposition 5.3. For $c_{1}>c_{2}$, a unique welfare maximizing equilibrium in the capacity stage exists. In this equilibrium, both firms install that level of capacity for which the marginal benefit of capacity is equal to marginal cost of capacity.

Proof. For $c_{1}>c_{2}$, the low-quality firm should start producing when the high-quality firm cannot serve all demand due to its capacity restriction. Hence, if demand is low, only the high-qualitative firm produces. If demand is increasing such that its output is constrained by its capacity, let's call this medium demand, the low-quality firm starts producing as well. For high levels of demand, both firms are producing at their capacity. When demand is low, the same reasoning applies as in the case of $c_{1} \leq c_{2}$ described above, yielding an equal contribution to the appropriate welfare function in the capacity stage as the first RHS term in (17). If demand increases such that $b>x_{1} \alpha^{-1}$, our so-called medium demand stage, the social optimal output follows from maximizing $\int_{0}^{z_{2}} p_{2}(\zeta, b, \cdot) d \zeta$ with respect to $z_{2}$ given $z_{1}^{*}=x_{1}$. The resulting optimal output for firm 2 yields therefore: $z_{2}^{*}=\theta \alpha b-\varphi x_{1}$. When $b>\left(\varphi x_{1}+x_{2}\right) / \theta \alpha$, i.e. for high levels of demand, the capacity constraints are binding for both firms. We refer to this boundary value using subscript $m$. The optimal output supplied for $b>b_{m}$ equals $x_{1}$ and $x_{2}$. Combining the optimal output for both firms over these three demand levels, yields the following welfare function in the capacity stage:

$$
\begin{aligned}
W\left(x_{1}, x_{2}, \cdot\right) & =-c_{1} x_{1}-c_{2} x_{2}+\int_{0}^{b_{l}\left(x_{1}, \cdot\right)} \int_{0}^{z_{1}^{*}(b, \cdot)} p_{1}^{l}(\zeta, b, \cdot) d \zeta f(b) d b \\
& +\int_{b_{l}\left(x_{1}, \cdot\right)}^{b_{m}\left(x_{1}, x_{2}, \cdot\right)}\left(\int_{0}^{x_{1}} p_{1}^{m}(\zeta, b, \cdot) d \zeta+\int_{0}^{z_{2}^{*}\left(x_{1}, b, \cdot\right)} p_{2}^{m}\left(\zeta, x_{1}, b\right) d \zeta\right) f(b) d b \\
& +\int_{b_{m}\left(x_{1}, x_{2}, \cdot\right)}^{\alpha^{-1}}\left(\int_{0}^{x_{1}} p_{1}^{h}\left(\zeta, x_{2}, b, \cdot\right) d \zeta+\int_{0}^{x_{2}} p_{2}^{h}\left(\zeta, x_{1}, b, \cdot\right) d \zeta\right) f(b) d b,
\end{aligned}
$$

where the subscripts $l, m$, and $h$ indicate that the inverse demand functions for both outputs, as specified in (1), are different for low, medium and high 
levels of demand. The resulting first order conditions for welfare maximizing are:

$$
\begin{aligned}
\frac{\partial W\left(x_{1}, x_{2}, \cdot\right)}{\partial x_{1}} & =\int_{b_{l}\left(x_{1}, \cdot\right)}^{b_{m}\left(x_{1}, x_{2}, \cdot\right)}\left(\frac{\partial}{\partial x_{1}} \int_{0}^{x_{1}} p_{1}^{m}(\zeta, b, \cdot) d \zeta\right) f(b) d b \\
& +\int_{b_{m}\left(x_{1}, x_{2}, \cdot\right)}^{\alpha^{-1}}\left(\frac{\partial}{\partial x_{1}} \int_{0}^{x_{1}} p_{1}^{h}\left(\zeta, x_{2}, b, \cdot\right) d \zeta\right) f(b) d b-c_{1}=0 \\
\frac{\partial W\left(x_{1}, x_{2}, \cdot\right)}{\partial x_{2}} & =\int_{b_{m}\left(x_{1}, x_{2}, \cdot\right)}^{\alpha^{-1}}\left(\frac{\partial}{\partial x_{2}} \int_{0}^{x_{2}} p_{2}^{h}\left(\zeta, x_{1}, b, \cdot\right) d \zeta\right) f(b) d b-c_{2}=0 .
\end{aligned}
$$

The above first order conditions have the same straightforward interpretation as before: marginal costs of capacity need to equal the marginal benefit (utility) of capacity. Only if both firms are capacity constrained, i.e. with high demand, adding an extra unit of capacity of the low-quality firm increases welfare. The marginal benefit of both capacities depends in this case depend on each other. For medium demand, adding an extra unit of capacity of the low-quality firm does not increase welfare because with this level of demand the low-quality firm is not capacity constrained.

\section{Numerical analysis: stochastic versus deterministic demand}

Although the first order conditions with respect to capacity have a straightforward interpretation, their structure prevents insightful analytical results for equilibria in the capacity stage from being available. Therefore, we perform a numerical analysis focussing on the differences between deterministic and stochastic demand. For such an analysis we need to define the distribution of $b$. The choice for a specific distribution does not alter the structure of the capacity-then-price game since the first order conditions are valid for any type of assumed distribution. We assume that $b$ follows a uniform distribution over the interval $\left(0, \alpha^{-1}\right]$, where the upper bound scales the model such that $D(0) \leq 1$. The model allows us to present numerical results over the entire relevant domain without making any additional arbitrary assumptions 
on parameter values other that on the cost parameters. ${ }^{14}$ Parameters $\varphi$ and $\theta$ are bounded by the restrictions that guarantee the existence of an equilibrium in pure strategies in the pricing stage as defined in Proposition 3.1. We vary the two parameters within these boundaries to assess their impact. ${ }^{15}$

\subsection{Profit maximising capacity levels}

Figure 1 depicts the relationship between total capacity and the cost level. In the deterministic case, this relationship is represented by a downward sloping linear line. In the stochastic case however, the relationship is non-linear. Figure $1 \mathrm{a}$ is based on equal capacity costs, whereas $c_{2}=\frac{1}{4} c_{1}$ in Figure $1 \mathrm{~b}$. If capacity costs are sufficiently low, it is rewarding to build capacity that stands idle for most of the time in order to serve peak demand. If capacity costs are large however, holding capacity just for high demand states is more costly and firms will build less than under deterministic demand. For

Total market capacity for $\theta=0.9$

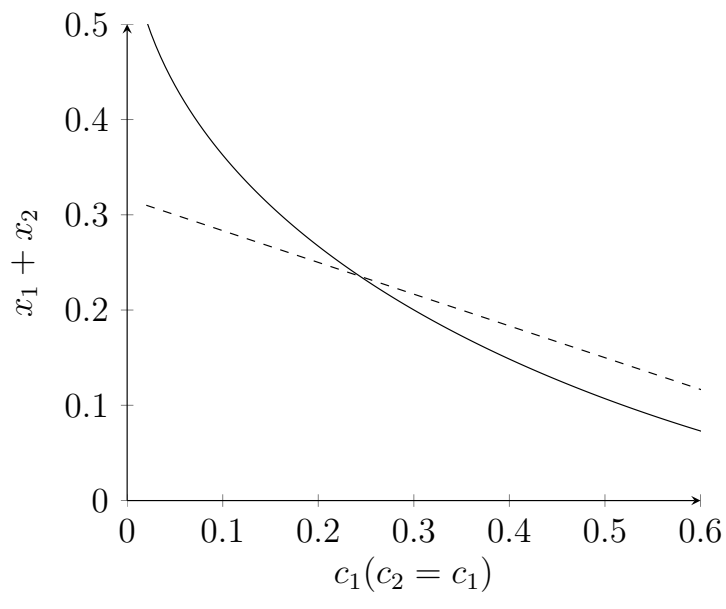

(a) Equal capacity costs

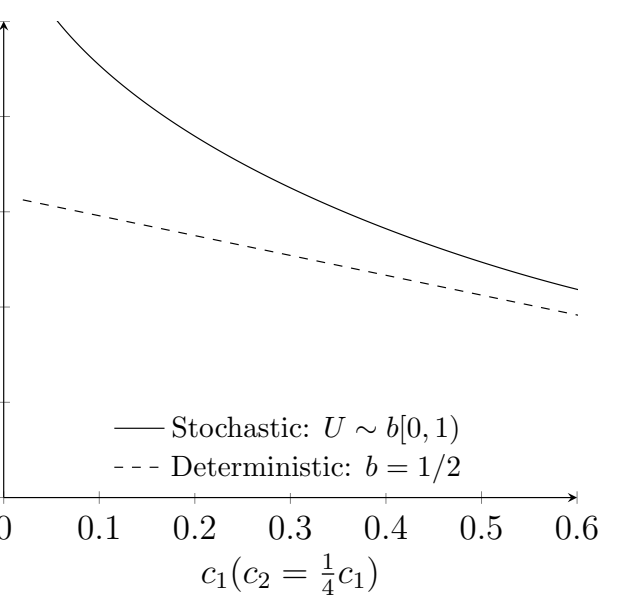

(b) Unequal capacity costs

Figure 1: Total market capacity for equal and unequal capacity costs.

\footnotetext{
${ }^{14}$ As mentioned above, using an upper bound of $b$ equal to $\alpha^{-1}$ merely scales the model. Hence, setting $\alpha$ to unity scales all prices, outputs, quantities and boundary values of $b$ as a fraction of the reservation price and maximum demand respectively.

${ }^{15}$ Since the degree of horizontal product differentiation $\varphi$ only has a minor effect on any of the outcomes presented here, only results for the limit case of its value nearing unity are reported.
} 
lower values of $\theta$, i.e. larger (perceived) quality differences, the pattern is similar, but the market becomes a monopoly at higher cost levels. If the low-quality firm has lower capacity costs, market capacity decreases slower with the cost level of the high-quality firm in without demand uncertainty (compare dashed line in $1 \mathrm{a}$ and $1 \mathrm{~b}$ ), and stronger so for stochastic demand (compare solid line in $1 \mathrm{a}$ and $1 \mathrm{~b}$ ). The intuition behind is as follows: the low costs of capacity (for the low-quality firm) yields it profitable to build capacity to cater for peak demand states of the world, whereas the costs of leaving the capacity idle in lower demand states is not such a heavy burden.

This intuition is confirmed in Figure 2. The lines, solid for the stochastic and dashed for the deterministic model, show the combinations of quality and cost differences for which both firms offer equal capacities, i.e. capacity isoquants. For all parameter sets to the right (left) of these lines, the low (high) quality firm offers more capacity than the high (low) quality firm. In the deterministic case, the capacity isoquant is determined by the equality $(1-\theta) \alpha=c_{1}-c_{2}$. At this equality, the quality difference exactly offsets the cost difference. The capacity isoquant for the stochastic case lies to the left of and above the capacity isoquant for the deterministic case, implying that the stochastic model yields an asymmetric outcome for parameter values that in a deterministic model would yield symmetric outcomes. The finding of an asymmetric result for values of $\theta$ and $c_{i}$ that would in the deterministic

\section{Capacity isoquants}

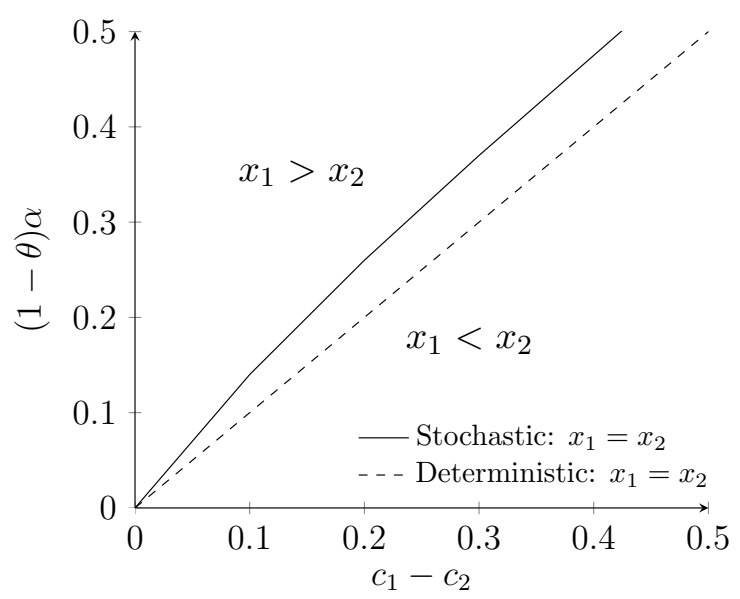

Figure 2: Capacity isoquants as function of $c_{1}, c_{2}=0.1$ and $\theta$. 
case yield symmetric outcomes is consistent with earlier results, reported by Reynolds and Wilson (2000) and De Frutos and Fabra (2011). Firm 1's high capacity costs withhold it from serving occasional high levels of demand, leaving more room for firm 2 to serve the market than it would have in the deterministic case. ${ }^{16}$

The profit maximizing capacities are plotted in Figure 3 for each firm and different levels of (perceived) quality differentiation. For $\theta=0.7$, both firms have equal capacities in the deterministic model because the quality difference offsets the cost difference. In the stochastic case, however, the capacity of the low cost, low-quality firm exceeds that of the higher quality firm. The difference increases as the difference in quality decreases. It is also obvious from Figure 3 that the difference in capacity levels increases more in the stochastic model compared to the deterministic case. ${ }^{17}$

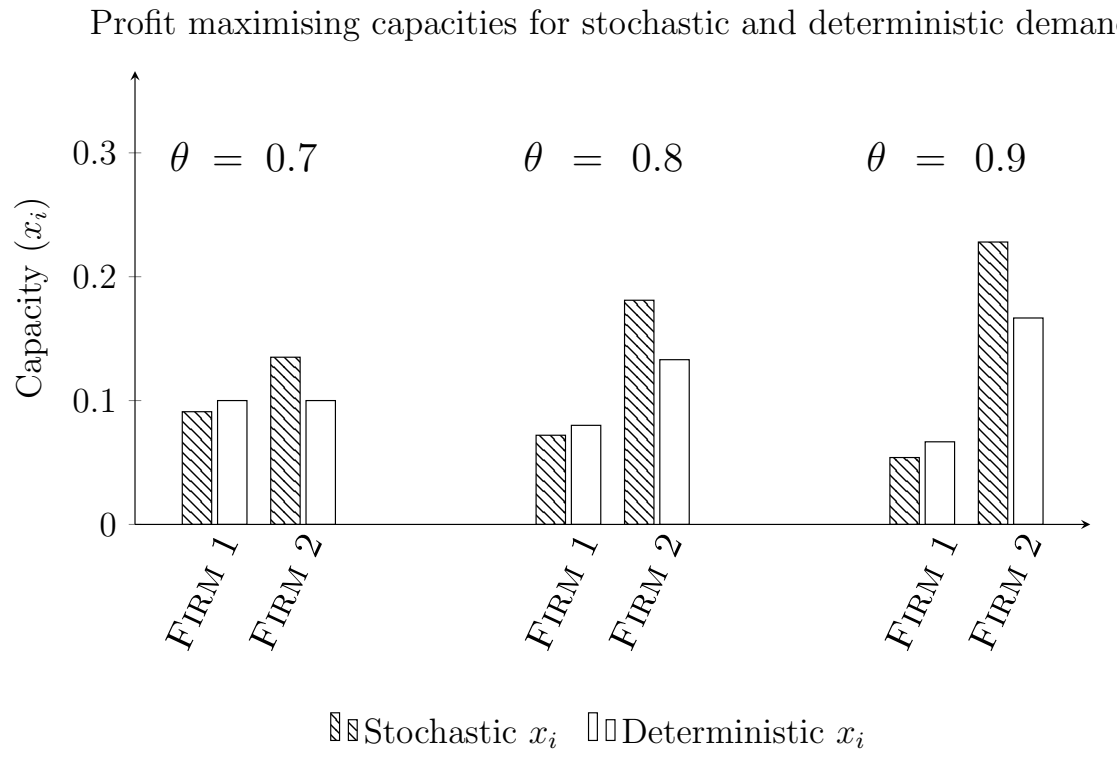

Figure 3: Profit maximising capacities for $c_{1}=0.4$ and $c_{2}=0.1$.

\footnotetext{
${ }^{16}$ If the cost level for both firms increases equally, the difference between restoring symmetric outcomes for stochastic versus deterministic demand, measured in $\theta$, becomes smaller. For high cost levels, symmetry is restored at the mentioned equality for both stochastic and deterministic demand.

${ }^{17}$ At equal costs, not shown here, the capacity of the high-quality firm exceeds that of
} 
Figure 4 provides the profit isoquants for combinations of quality differences and cost differences. The pattern is fairly similar to that in Figure 2 , although the difference between the stochastic and deterministic case is smaller for profits than for capacities. Like in the case of capacities, there is a range of parameters for which the deterministic model predicts higher profits for the high-quality firm, whereas the stochastic model predicts higher profits for the low-quality firm.

\subsection{Impact of naive regulation and market power on welfare}

The difference between the deterministic and the stochastic version of the model allows us to analyse the situation that we label as naive regulation. Under such naive regulation, the regulator assumes that the world is deterministic, whereas it is in fact stochastic. We use the same definition of efficiency as, amongst others, Acemoglu et al. (2009): the ratio of welfare in equilibrium relative to the first-best outcome. The first-best outcome in this case is defined as welfare maximisation by a regulator who acknowledges that the world is stochastic, as discussed in Section 5.2.

Figure 5 compares the efficiency of naive regulation and the market out-

Profit isoquants

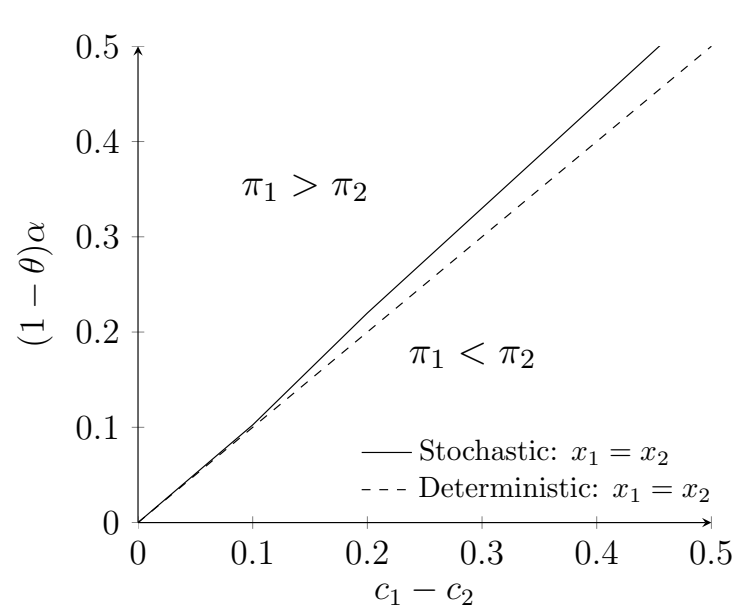

Figure 4: Profit isoquants as function of $c_{1}, c_{2}=0.1$ and $\theta$.

the low cost firm, and again the differences are larger in the stochastic case. 
come without regulation for different degrees of product differentiation. If the quality difference is exactly offset by the cost difference, here at $\theta=0.7$, naive regulation nearly reaches the first-best level of welfare. If the quality difference is smaller than the cost difference, the efficiency of naive regulation drops instantly to a level below that of the unregulated market outcome. If the quality difference is larger than the cost difference the drop is not instant, but the efficiency of naive regulation still drops fast. The bad performance of naive regulation is because it ignores the fact that a mix of low- and high-quality capacity is welfare improving if demand is uncertain: for the given cost levels and $\theta>0.7$, the naive regulator only installs capacity of the low-quality firm, not taking into account the realised level of demand. However, in reality, for a whole range of low levels of demand it would have been better to have the high-quality firm producing and leave only occasional peak demand to be served by the low-quality firm. ${ }^{18}$ Only if the differences in quality and capacity costs nearly offset each other, the costs of having no mix of production is absent. Given that competition without regulation results in installed positive capacities for both firms, Figure 5 suggests that

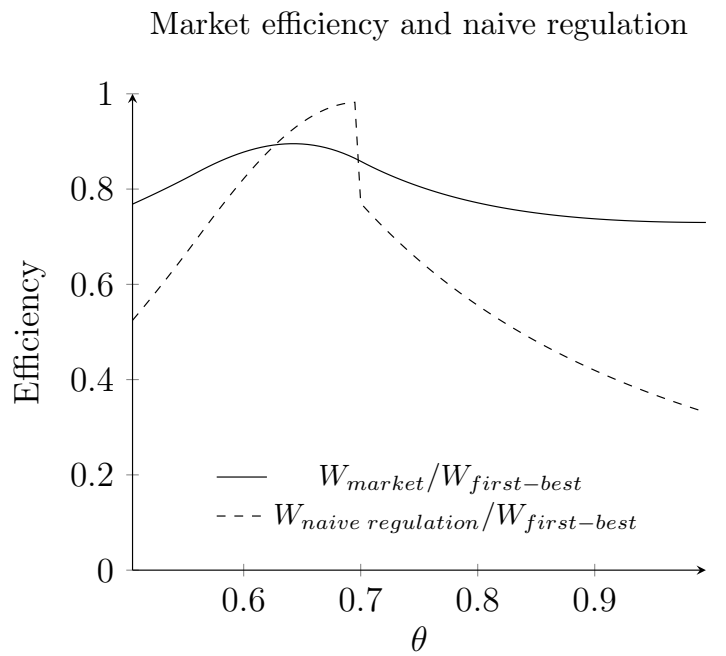

Figure 5: Efficiency for different levels of $\theta$ with $c_{1}=0.4$ and $c_{2}=0.1$.

\footnotetext{
${ }^{18}$ For $\theta<0.7$, only the high-quality firm installs positive capacity under naive regulation. As a result, in reality, the society incurs too high capacity costs to serve occasional peak demand.
} 
naive regulation only outperforms the market outcome in a small area where the quality difference is approximately equal to the cost difference.

We check the robustness of this result in Figure 6. The graph depicts all combinations of cost and quality differences for which naive regulation leads to the same level of welfare as the unregulated market outcome. Only in the small band where cost and quality differences are about equal, we find that naive regulation leads to higher welfare than the market outcome. This holds for about 10 per cent of all possible parameter values. This suggests that ignoring the stochastic nature of demand comes at a high risk of regulation that reduces welfare rather than increasing it. This clearly establishes the importance of our analysis and results.

Free market vs. naive regulation

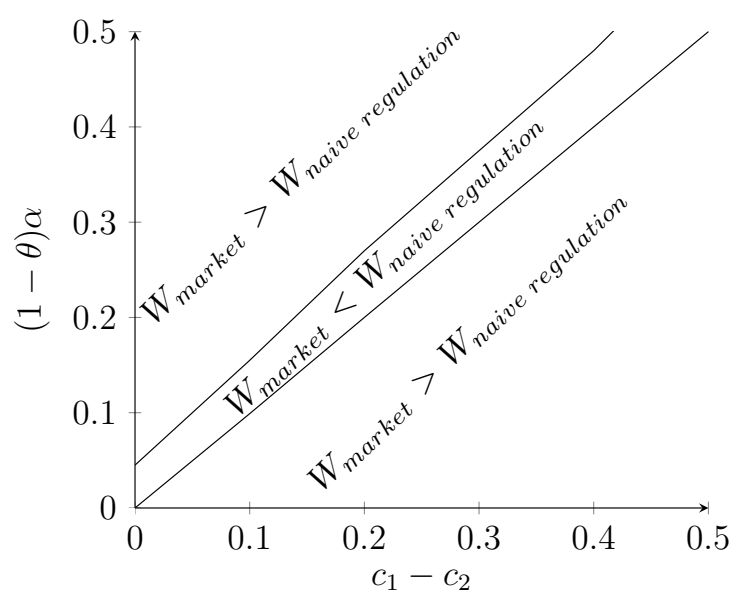

Figure 6: Contour lines for welfare regimes as function of $c_{1}, c_{2}=0.1$ and $\theta$.

\section{Conclusion}

In this article we studied capacity-then-price competition under demand uncertainty in a duopoly with product differentiation. Besides the academic interest in finding approaches to solve such multi-stage strategic games, following the seminal paper by Kreps and Scheinkman (1983), our study and findings may be highly relevant for market and policy analysis for a great number of industries where capacity is costly and outputs cannot be stored, 
such as scheduled transport services, telecommunication services and electricity generation.

We considered a two-stage duopoly game, where firms set simultaneously capacities in the first, and prices in the second stage. The actual level of demand is known only after setting capacity and varies between time periods. Using backward induction, we solved the pricing stage by defining three different regions: contested monopoly, residual monopoly and Bertrand Edgeworth duopoly. These regions are based on the actual level of demand and installed capacities in the first stage. We established a unique equilibrium in pure strategies in both the pricing and capacity stage when the market is characterised by a sufficient degree of vertical product differentiation relative to horizontal differentiation. In the capacity stage, firms equate their marginal capacity costs to the expected marginal revenue of capacity over the relevant regions. To the best of our knowledge, this is the first study to find pure strategy equilibria for capacity-then-price games addressing explicitly both demand uncertainty and product differentiation.

In case of relative low (high) capacity costs, profit maximising capacities are higher (lower) under stochastic demand compared to deterministic demand. If demand is stochastic and capacity costs are low, it is economically viable to hold a large amount of spare capacity to serve high demand states of the world if they occur. For asymmetric capacity costs, the results show that under stochastic demand the model yields asymmetric outcomes even if the cost difference exactly offsets the quality difference. In particular, the capacity costs prevent the high-quality firm to install capacity to serve occasional high levels of demand. As a result, the low-quality firm will install more capacity under demand uncertainty, compared to deterministic demand.

If a welfare maximizing regulator ignores the fact that demand is stochastic (labelled as naive regulation), regulation will only outperform the market in terms of welfare for a narrow band of parameters, about 10 per cent of the feasible parameter space, where the quality difference is approximately equal to the cost difference. For other parameter sets, naive regulation leads to substantial welfare losses due to not providing a mix of low- and high-quality capacity. This clearly stresses the importance of taking the stochastic nature of demand into account, both regulation and in economic research.

Future research might address testing our model and key findings empirically, where adequately identifying and measuring the degree of product differentiation is a true challenge. Finally, one could argue that firms in real- 
ity may choose the degree of product differentiation. Hence, extending the analysis to the case of endogenous quality choice would be a promising venue for future research. 


\section{Bibliography}

Acemoglu, D., Bimpikis, K., and Ozdaglar, A. (2009). Price and capacity competition. Games and Economic Behavior, 66(1):1-26.

Benassy, J. P. (1989). Market Size and Substitutability in Imperfect Competition: A Bertrand-Edgeworth-Chamberlin Model. The Review of Economic Studies, 56(2):217-234.

De Frutos, M. and Fabra, N. (2011). Endogenous capacities and price competition: The role of demand uncertainty. International Journal of Industrial Organization, 29(4):399-411.

Gabszewicz, J. J. and Poddar, S. (1997). Demand fluctuations and capacity utilization under duopoly. Economic Theory, 10(1):131-146.

Gal-Or, E. (1984). Price dispersion with uncertain demand. International Economic Review, 25(2):441-457.

Hviid, M. (1991). Capacity constrained duopolies, uncertain demand and non-existence of pure strategy equilibria. European Journal of Political Economy, 7(2):183-190.

Kreps, D. M. and Scheinkman, J. A. (1983). Quantity Precommitment and Bertrand Competition Yield Cournot Outcomes. The Bell Journal of Economics, 14(2):326-337.

Lepore, J. J. (2012). Cournot outcomes under Bertrand-Edgeworth competition with demand uncertainty. Journal of Mathematical Economics, 48(3):177-186.

Martin, S. (1999). Kreps And Scheinkman With Product Differentiation: An Expository Note. CIE Discussion Papers 1999-11, University of Copenhagen, Centre for Industrial Economics.

Osborne, M. J. and Pitchik, C. (1986). Price competition in a capacityconstrained duopoly. Journal of Economic Theory, 38(2):238-260.

Reynolds, S. S. and Wilson, B. J. (2000). Bertrand Edgeworth Competition, Demand Uncertainty, and Asymmetric Outcomes. Journal of Economic Theory, 92(1):122-141. 
Schulz, N. (1999). Capacity constrained price competition and entry deterrence in heterogeneous product markets. Würzburg Economic papers 1999-7, University of Würzburg.

Vives, X. (1999). Oligopoly Pricing: Old Ideas and New Tools. The MIT Press, Cambridge, Massachusetts.

Yin, X. and Ng, Y.-K. (1997). Quantity Precommitment and Bertrand Competition Yield Cournot Outcomes: A Case with Product Differentiation. Australian Economic Papers, 36(68):14-22.

Young, D. T. (2010). Endogenous Investment and Pricing under Uncertainty. The B.E.Journal of Theoretical Economics, 10(1):1-27. 